\title{
Paleoecological analasis of the miospore assemblages from the borehole 39, Moscow region, Russia
}

\author{
Dmitry A. Mamontov \\ Lomonosov Moscow State University, Department of Paleontology; Moscow, Russia; e-mail: palynologist.dm@mail.ru \\ (c) 2015 Authors. This is an open access publication, which can be used, distributed and reproduced in any medium according \\ to the Creative Commons CC-BY 4.0 License requiring that the original work has been properly cited.
}

Palynological material was obtained from Upper Visean deposits in the borehole No 39 that is located on the left bank of the Oka River, on $105 \mathrm{~km}$ to the south-east of the Moscow in the Serpukhov district. The lithological sequence of the borehole generally consist of the limestones, stigmarian limestones, interbedded with clays and siltstones. Total twenty five palynological samples from the sandy siltstones and charcoal clays (deep interval 29.4-33.25 m) have been collected. All samples contained abundant well-preserved miospores. Two palynoassemblages have been defined. The palynoassemblage $S 1$ is described from the sandy siltstone and stigmarian limestones of the depth interval $29.4-29.59 \mathrm{~m}$. The palynoassemblage $\mathrm{S} 2$ is established from the coaly dark clays that occurred at the depth interval $29.64-33.25 \mathrm{~m}$. All palynoassemblages are dominated by Lycospora pusilla. Based on both the presence Cingulizonaes bialatus, Triquitrites comptus, (index-species of the CBd palynozone) and the occurrence of the Late Visean species Tripartites vetustus, Triquitrites marginatus, Schulzospora campyloptera, Calyptosporites arenaceous the age of the palynoassemblages is defined as transitional Aleksinian-Mikhaylovian. The results well corresponded with data of miospore zonal scheme for Carboniferous of Russian Platform (Makhlina 1993).

Paleoecological interpretation of the obtained palynoassemblages has been carrying out. General model of the paleoecological analysis is explained by the connection between the Carboniferous miospore taxa and their parent plants. Natural affinity of the miospores is determined by the comparison of dispersed material with the in situ spore findings that are elucidated in paleobotanical articles (more detail see Balme 1995, Orlova et al. 2014). In concordance with the comparison of the dispersed spores and in situ data, the miospore genera of the palynoassemblages have been subdivided into six paleobotanical patterns: arborescent lycopsids (Lycospora-producing plants), sub-arborescent lycopsids were produced the "densospores" (Densosporites, Vallatisporites, Cingulizonates), spores of ferns (Leiotriletes, Punctatisporites, Granulatisporites, Cyclogranisporites, Knoxisporites, Raistrikia, Tripartites, Triquitrites, Acanthotriletes, Convolutispora), miospores (prepollen) of seed ferns (Schulzospora, Remysporites, Geminospora, Rotaspora), spores of the sphenopsids (pars Calamospora) and pattern of unknown natural affinity (Diatomozonotriletes, Camarozonotriletes, Iugisporis, Simozonotriletes, Waltzispora, Calyptosporites). Abovementioned paleobotanical patterns are generalized into three paleoecological units: forest mire (arborescent and sub-arborescent lycopsids), non-forest mire (ferns, seed ferns and sphenopsids) and problematic one (unknown natural affinity). Accordingly, palynoassemblage S1 is dominated by arborescent lycopsids (66\%). Sub-arborescent lycopsids (11\%) and ferns (13\%) were quite common in the plant communities. The seed ferns elements (2\%) and sphenopsids (3\%) were rare in the local palaeoflora. On the one side the forest-mire related miospores were increased upward the sequence (from $70 \%$ up to $88 \%$ ), on the other side the percentage of the non-forest mire elements (from $26 \%$ up to $8 \%$ ) were constant decreased in the same direction. The high percentage of forest mire unit is largely due to short 
predominance of the sub-arborescent lycopsids (21\%). Palynoassemblage S2 is differed from the preceding one by the increased role of the arborescent lycopsids (75\%) in the plant communities. The percentage of the sub-arborescent lycopsids $(2 \%)$ is distinctive low. Content of the ferns (11\%) is slightly decreased versus the previous palynoassemblage. Ratio of the sphenopsids (5\%) and seed ferns (3\%) is easily enlarged. Forest mire vegetation type was constantly dominated (75\%) in the plant cover of the studied locality while the non-forest one $(19 \%)$ was less common than the same from the palynoassemblage $\mathrm{S} 1$. The percentage of the ferns (from 3\% up to 21\%) and sphenopsids (from $3 \%$ up to $7 \%$ ) is gradually increased during the deposition time of the palynoassemblage S2.

As result of the paleoecological interpretation of the palynoassemblage the change of the vegetation types during Late Visean time has been recorded. Generally content of the forest mire related miospores is decreased upward the section while the percentage of the non forest mire elements is constantly increased. Most probably that short prevalence of the sub-arborescent lycopsids at the uppermost part of the palynoassemblage S1 can be related with initial transgression phase. From the one side this proposal is well corresponded with data of the Habib \& Groth (1967) referred that Lycospora-producing arborescent lycopsids were more sensitive for higher salinity during the sea onlap and it could replaced by the stress-tolerant Densospores-producing subarborescent lycopsids. From the other side the uppermost part of the palynoassemblage $S 1$ determined from the stigmarian limestone that indicated the brackish condition. Besides the high percentage and diversity of the fern derived miospores coincides with the high portion of clastic material in deposits. It is explained by that the fern preferred open and opportunistic condition of sand bars. Apparently, the plant cover change is very similar to the same vegetation type's ratio was marked by the previous researches in the Upper Visean localities from the Kaluga and Tula regions (Mamontov et al. 2012).

The research was supported by Russian Foundation for Basic Researches, project No. 15-04-09067.

\section{REFERENCE}

Balme B.E., 1995. Fossil in situ spores and pollen grains: an annotated catalogue. Review of Palaeobotany and Palynology, 87, 81-323.

Habib D. \& Groth P.K.H., 1967. Paleoecology of migrating Carboniferous peat environments. Palaeogeography, $\mathrm{Pa}$ laeoclimatology, Palaeoecology, 3, 185-195.

Makhlina M.Kh., Vdovenko M.V., Alekseev A.S., Byvsheva T.V., Donakova L.M., Zhulitova V.E., Kononova L.I., Umnova N.I. \& Shick E.M., 1993. Lower Carboniferous of the Moscow Syneclise and Voronezh Anteclise. Nauka Press, Moscow [in Russian].

Mamontov D.A., Orlova O.A. \& Anikeeva E.V., 2012. Comparative analysis of the Late Visean vegetation based on palynological data (southern wing of Moscow Syneclise, Russia). Proceedings of the XIII International Conference of Young Geologists. Herl'any 26-28.04.2012, 18-20.

Orlova O.A., Mamontov D.A. \& Snigirevsky S.M., 2014. Late Visean (Mississippian) vegetation of the north-western part of Russia according to palaeobotanical and palynological data. Historical Biology: An International Journal of Paleobiology. DOI: 10.1080/08912963.2014.899117. 